Uludag Univ. J. Fac. Vet. Med.

35 (2016), 1,2: 57-60

\title{
Bir Buzağıda Salter-Harris Tip I Metacarpus Kırığının Açılı Kama Plağı İle Sağaltımı
}

\author{
Hakan SALCI ${ }^{1}$
}

Uygur CANATAN ${ }^{1}$

Melike ÇETIN ${ }^{1}$

\begin{abstract}
Özet: Bu olgu sunumu ile bir buzağıda Salter-Harris Tip I metacarpus kırığında uyguladığımız $90^{\circ}$ açılı kama plağının postoperatif klinik ve radyolojik bulgularının rapor edilmesi amaçlanmıştır. Holstein melezi, 3,5 aylık, dişi bir buzağı ön bacağında kırık şikayeti ile kliniklerimize getirildi. Klinik muayenede, buzağının vital parametreleri normaldi ancak inspeksiyonda sağ ön ekstremitede şiddetli topallık, metacarpophalangeal eklem proksimalinde şişkinlik ve sıyrık yarası gözlendi. Ortopedik muayenede, bölgede spesifik kırık bulguları saptandı. Radyografik muayenede, sağ metacarpusun distal fizeal hattan kırllarak (Salter-Harris Tip I) disloke olduğu belirlendi. Hasta sahibine bilgi verildi ve genel anestezi hastanın operasyonuna karar verildi. Kırığın redüksiyonu sonrası fiksasyon için $90^{\circ}$ açılı kama plağı kullanıldı. Plağın kama kısmı epifiz kısma çakıldı ve plaka vidalarla proksimal fragmente tespit edildi. Postoperatif atel destekli bandaj uygulandı. Rutin analjezik ve antibiyotik uygulama prosedürü reçete edildi. Buzağının postoperatif 15. gün kontrolünde, kırık bölgesinde stabilizasyonun devam ettiği, buzağının ilgili ekstremitesini bandajsız kullanabildiği gözlendi.
\end{abstract}

Anahtar Kelimeler: Salter-Harris Tip I, metacarpus kırığı, açılı kama plağı, buzağı.

\section{Treatment with Angled Blade Plate of Salter-Harris Type I Metacarpus Fracture in a Calf}

\begin{abstract}
Reporting to postoperative clinical and radiological results of $90^{\circ}$ angled blade plate applied in SalterHarris Type I metacarpus fracture in a calf was aimed with this case presentation. A Holstein mix breed, 3.5month-old, female calf was presented with the complaint of broken forelimb In the clinical examination, vital parameters of the calf was normal; however, severe lameness on the right forelimb, swelling on the proximal site of the metacarpophalangeal joint and excoriation was seen in the inspection. In the orthopedic examination, specific signs of fracture were detected. In radiographic examination, a dislocation of the right metacarpus following to distal epiphyseal line fracture (Salter-Harris Type I) was determined. It was informed to the patient owner and operative approach to the patient under general anesthesia was decided. After reduction of the fracture, $90^{\circ}$ angled blade plate was used for fixation. The blade part of the plate was driven to epiphysis and plate was fixed to the proximal fragment with screws. Postoperative, atel supported bandage was applied. A routine analgesic and antibiotic application procedure was prescribed. In postoperative 15th day control of the calf, It was observed that stabilization was continuing on the fractured region, the calf was standing to its extremity without bandage.
\end{abstract}

Key Words: Salter-Harris Type I, metacarpus fracture, angled blade plate, calf. 


\section{Giriş}

Ekstremite kırıkları içerisinde metacarpus ve metatarsus kırıkları sığırlarda en sık karşılaşılan kırıklardır ${ }^{2,3,6,8}$ ve tüm kırıkların yaklaşık $\% 50$ 'sini oluşturur ${ }^{5}$. Metacarpus kırıkları, metatarsus kırıklarından daha fazla görülmektedir ${ }^{6}$ ve nedeni olarak genellikle her çeşit travmalar, hayvanların birbirlerini tekmelemesi ve güç doğuma yanlış müdahale bildirilirr ${ }^{3,5,6}$. Güç dogum ve hatalı doğuma yardım manüplasyonları sonucu yumuşak doku lezyonları ile birlikte metacarpus, metatarsus, mandibula, femur, tibia, antebrachium ve kaburga kırıkları şekillenir $^{1}$.

Metacarpus ve metatarsus kırıkları genellikle Salter-Harris Tip I ve II epifizer ya da orta diafizer kırıklar olarak sunulur ${ }^{3,6}$. Klinik olarak, akut şiddetli topallık gözlenir ve kırktan şüphelenilen olgularda ise kesin tanı topallık bulunan ekstremitenin radyolojik muayenesi ile konulur ${ }^{6}$. Buzağılarda kapalı metacarpus ve metatarsus kırıklarının prognozu genellikle olumludur ve uygulanılan sağaltım tekniğine göre genelde erken dönemde fonksiyonel iyileşme görülür ${ }^{8}$. Sunulan bu olgu ile, bir buzağının metacarpus kırığında şekillenmiş Salter-Harris Tip I kırığının, $90^{\circ}$ açılı kama plağı ile yapılan osteosentezinin postoperatif klinik ve radyolojik bulgularının rapor edilmesi amaçlanmıştır.

\section{Olgunun Tanımı}

Holstein melezi, 3,5 aylık, dişi bir buzağ 1 ön sağ bacağında şekillenmiş kırık şikayeti ile Uludağ Üniversitesi Veteriner Fakültesi Cerrahi Anabilim Dalı Klinikleri'ne getirildi. Hasta sahibi; 3 gün önce transport esnasında buzağının sağ ön ayağının kamyonet kapağına sıkıştığını ve bu esnada ilgili bacakta kırık şekillendiğini bildirdi.

Genel muayene fizyolojik parametreleri normal olan buzağının, sağ ön ekstremitesinde şiddetli topallık belirlendi. Sağ metacarpofalangeal eklemin proksimalinde şişkinlik ve sıyrık yaras1 görüldü (Şekil 1). Palpasyonda ilgili bölgede anormal hareket, ağrı, deformasyon ve krepitasyon tespit edildi.

Radyolojik olarak, dorsopalmar radyografide sağ metacarpusun distal epifizinde epifizer dekolman şekillendiği (Salter Harris Tip I) ve distal fregmanın mediale doğru disloke olduğu belirlendi. Mediolateral radyografide distal fregman ayrıca dorsale doğru da yer değiștirmişti (Şekil 2a-b).
Klinik ve radyolojik muayeneler sonucu sağ metacarpus'un distal epifizinde kapalı, disloke Salter-Harris Tip I tanısı konuldu. Hasta sahibine patoloji hakkında bilgi verildi ve alınan izinle osteosentez operasyonuna karar verildi.

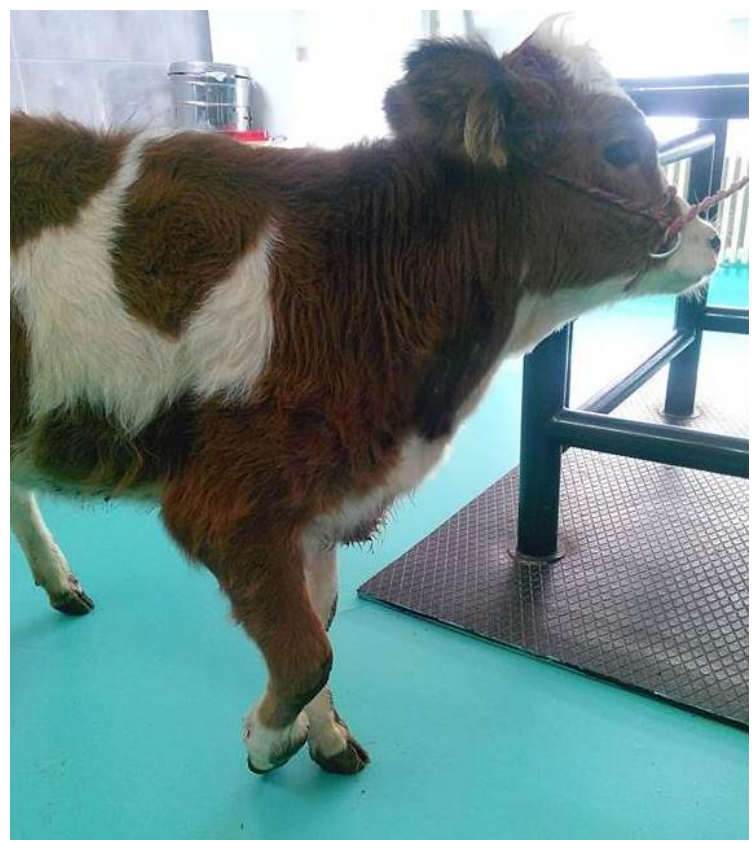

Şekil 1. Olgunun klinik görünümü.

Figure 1. Clinical view of the case.
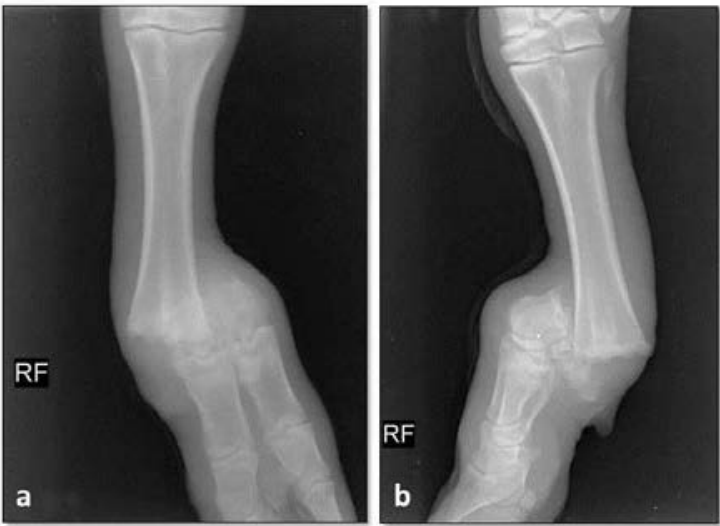

Şekil 2. Olgunun dorsopalmar (a) ve lateral (b) radyografilerinde kırı̆̆ın görünümü.

Figure 2. Appearance of the fracture on the dorsopalmar (a) and lateral (b) radiographs.

Sedasyon amaciyla $0,02 \mathrm{mg} / \mathrm{kg}$ dozda xylazine HCl (Alfazine ${ }^{\circledR}$, Egevet, Türkiye) im. olarak verildi. Ketamin HCl'nin (Alfamine ${ }^{\circledR}$, Egevet, Türkiye) $4 \mathrm{mg} / \mathrm{kg}$ dozda im. uygulanması ile indüksiyon sağlandı. Anestezinin idamesi için aynı enjektörde ketamin $\mathrm{HCl}$ ve diazepam (Diazem ${ }^{\circledR}$, Deva, Türkiye) kombinasyonu hazırlandı ve gerektiğinde iv. olarak uygulandi. 
Buzağı operasyon masasına alındı ve regio metacarpi'nin tıraş ve dezenfeksiyonu sonrasında bölge steril örtülerle sınırlandırıldı. Metacarpusun distal 1/3’ünü içine alan lateralden longitudinal düz bir deri ensizyonu yapıldı. Subkutan doku ve kasların diseksiyonu sonrası kırık hattına ulaşıldı. Fizeal hattan ayrılmış olan distal fregmanın repozisyonu, redüksiyonu ve fiksasyonu sonrası, $90^{\circ}$ açılı kama plağının kama kısmı önce epifize çakıldı ve takiben proksimal fregmana plak 3 adet kortikal vida ile sabitlendi (Şekil 3). Rutin cerrahi kapama sonras1 ilgili ekstremiteye PVC atel ile destekli bandaj uyguland.

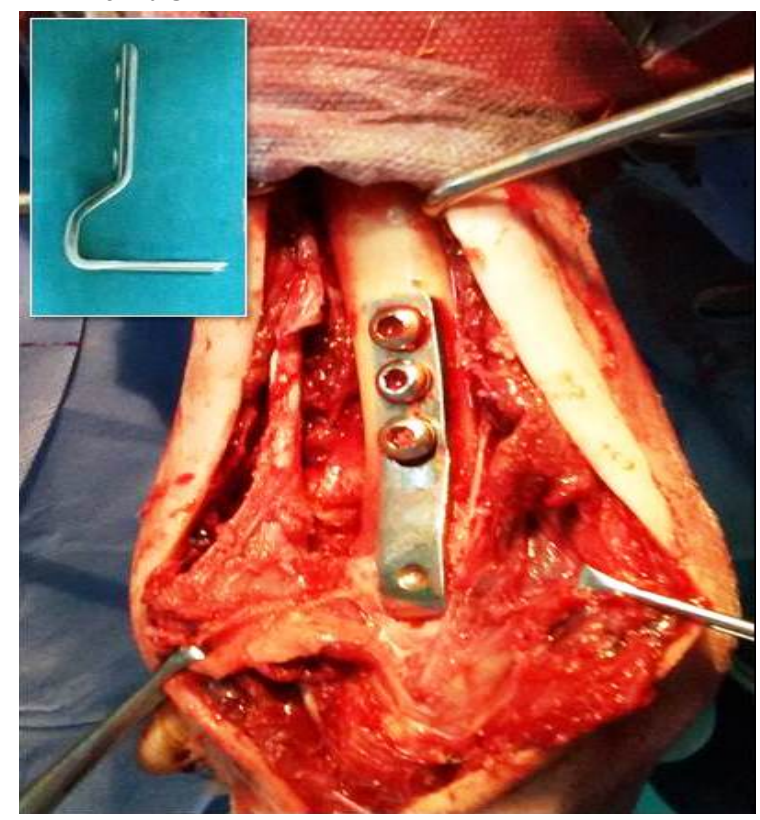

Şekil 3. $90^{\circ}$ açılı kama plağının (küçük resim) intraoperatif görünümü.

Figure 3. Intraroperative view of the $90^{\circ}$ angled wedge plate (small picture).

Postoperatif radyolojik incelemede uygulanılan plaka ile redüksiyon ve fiksasyonun sağlanmış olduğu belirlendi (Şekil 4). Postoperatif 7 gün süreyle analjezik ve antibiyotik uygulandı. Buzağının postoperatif 15 . günde dikişleri alındı ve yapılan muayenede operasyon bölgesinde stabilizasyonun devam ettiği, ilgili ayağına yük verebildiği ve bandajsız rahatça yürüdüğü görüldü (Şekil 5). Taburcu edildikten sonraki takip eden dönemde olgunun radyolojik kontrolü mümkün olamadığı gibi 15. ayda hasta sahibi ile yapılan telefon görüşmesinde hastanın ekstremitesini rahatça kullanabildiği ve herhangi bir problemin olmadığı bildirildi.

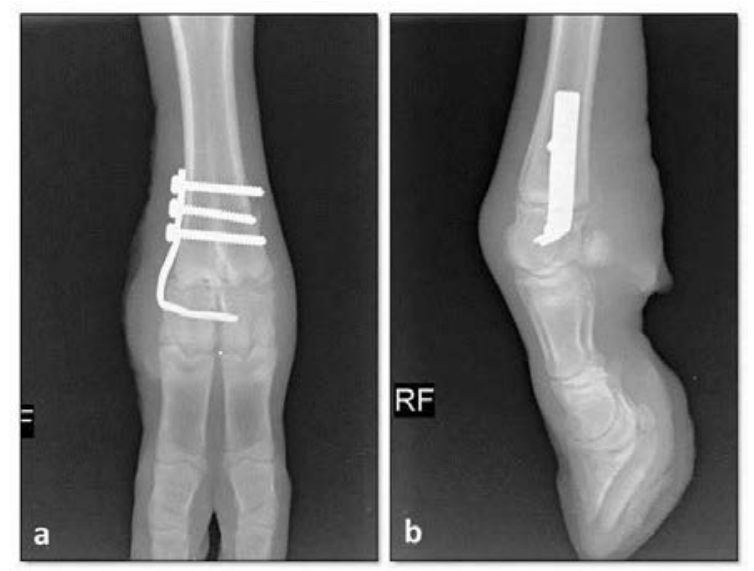

Şekil 4. Postoperatif dorsopalmar (a) ve lateral (b) radyografiler, $90^{\circ}$ açılı kama plağ ile yapılmış osteosentez sonrası kırığın redüksiyonu.

Figure 4. Postoperative dorsopalmar (a) and lateral (b) radiographs, reduction of the fracture with $90^{\circ}$ angled wedge plate following osteosentesis.

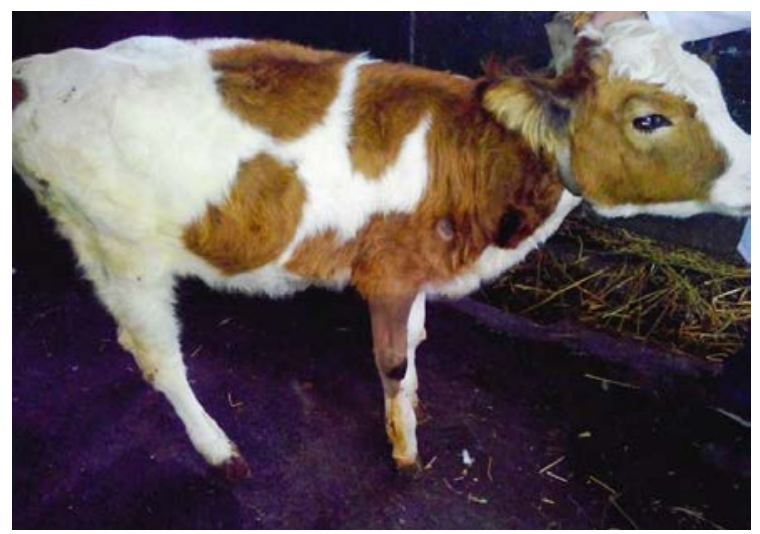

Şekil 5. Olgunun taburcu edilmeden önceki klinik görünümü.

Figure 5. Clinical view of the case before discharged.

\section{Tartışma}

Yeni doğan buzağılarda özellikle güç doğum ya da transport esnasinda meydana gelen travmatik durumlar nedeniyle çeșitli kemik k1rıklarıyla karşılaşılmaktadır. Karşılaşılan kemik kırıklarının çoğunu metacarpus ve metatarsus kırıkları oluşturur ${ }^{5}$. Bu kırıklar epifizer ya da diafizer kırıklar olarak karşımıza çıkar ${ }^{6}$. Sunulan olgumuzda kırığı̆ şekillenme nedeni olarak transport esnasinda meydana gelen travmatik bir durum tespit edilmiştir. Kırık olgusu sağ metacarpus'un distal epifizeal dekolmanı (Salter Harris tip I) olarak tanınmıştır. 
Buzağılarda kırık sağaltımında, hayvanın ağırlığı ve kırık tipi dikkate alınarak farklı tedavi teknikleri uygulanır. Genellikle şekillenen kırık olgularında atelli bandaj uygulaması tedavi seçeneğini oluşturmaktadır ${ }^{3}$ ve özellikle kapalı, basit, diafizer bölgeyi içeren falanks, metacarpus ve metatarsus kırıklarında uygulanmaktadir ${ }^{1,8}$. Ayrıca metacarpus ve metatarsus kıriklarında operatif eksternal fiksasyon yöntemleri de tercih edilmektedir ${ }^{3,6}$. Kırık fragmentlerinin disloke olduğu, parçalı ve komplike kırıklarda operatif internal fiksasyon yöntemleri (intramedullar pin, serklaj, vida, plaka, interlocking pin vb.) kullanılmaktadır ${ }^{1}$. Olgumuzdaki kırı̆̆ın yerleşimi epifizer bölgede olduğu için plaka ve vida kullanılarak internal fiksasyon yöntemi ile sağaltım seçeneği tercih edilmiştir.

İnsanlarda karşılaşılan supraconduler femur kırıklarında, fiksasyon için seçilen çeșitli implantlar arasında farklı açıya sahip "açılı kama plağı" kullanılmaktadır. Bu plaklar ile yapılan osteosentez operasyonu kolay ve güvenli olmakta, ayrıca biyomekanik açıdan da olumlu sonuçlar sergilemektedir, ${ }^{4,7,10}$. Özellikle kırık bölgesine tekniğine uygun olarak yerleştirildiğinde, kemiğin aksiyal ve rotasyonel kuvvetlere karşı dirençli hale geldiği görülmektedir ${ }^{9}$. Bu literatür bilgileri göz önüne alınarak, metacarpusta şekillenmiş Salter-Harris Tip I epifiz kırığında, $90^{\circ}$ açılı kama plağı kullanılarak osteosentez operasyonu gerçekleştirilmiş ve cerrahi başarı elde edilmiștir.

Sonuç olarak, postoperatif klinik ve radyolojik muayene bulgular temelinde buzağılarda metacarpusun epifizer kırıklarında $90^{\circ}$ açılı kama plağı ile osteosentezin başarılı bir şekilde uygulanılabileceği görülmüştür.

\section{Kaynaklar}

1. Aksoy, Ö., Özaydın, İ., Kılıç, E., Öztürk, S., Güngör, E., Kurt, B., Oral, H. 2009. Evaluation of fractures in calves due to forced extraction during dystocia: 27 cases (2003-2008). Kafkas Üniv Vet Fak Derg, 15(3), 339-344.

2. Belge, A., Akın, İ., Gülaydın, A., Yazıcı, M.F. 2016. The treatment of distal metacarpus fracture with locking compression plate in calves. Turk $J$ Vet Anim Sci, 40, 234-242.

3. Bilgili, H., Kürüm, B., Olcay, B. 1999. Buzağ1larda uzun kemik kırıklarının ilizarov tekniği ile sağaltım olanaklarının araştırılması. Ankara Üniv Vet Fak Derg, 46, 299-308.

4. Crist, B.D., Khalafi, A., Hazelwood, S.J., Lee, M.A. 2009. A biomechanical comparison of locked plate fixation with percutaneous instertion capability versus the angled blade plate in a subtrochanteric fracture gap model. J Orthop Trauma, 23(9), 622-627.

5. Demirkan, İ., Korkmaz, M., Çevik-Demirkan, A. 2009. Simental ırkı bir buzağıda aşağı ekstremite amputasyonu ve protez uygulamasi. Kocatepe Vet Derg, 2(2), 39-43.

6. Fubini, S., Ducharme, N. 2004. Farm Animal Surgery, Saunders, St. Louis.

7. Jaakkola, J.I., Lundy, D., Moore, T., Jones, B., Ganey, T.M., Hutton, W.C. 2002. Supracondylar femur fracture fixation: Mechanical comparison of the $95^{\circ}$ condylar side plate and screw versus $95^{\circ}$ angled blade plate. Acta Orthop Scand, 73(1), 72-76.

8. Mulon, Y.V. 2013. Management of long bone fractures in cattle. In Pract, 35, 265-271.

9. Petsatodis, G., Chatzisymeon, A., Antonarakos, P., Givissis, P., Papadopoulos, P., Christodoulou, A. 2010. Condylar butress plate versus fixed angle condylar blade plate versus dynamic condylar screw for supracondylar intra-articular distal femoral fractures. J Orthop Surg, 18(1), 35-38.

10. Vandenbussche, E., LeBaron, M., Ehlinger, M., Flecher, X., Pietu, G., SOFCOT. 2014. Bladeplate fixation for distal femoral fractures: A case-control study. Orthop Traumatol Surg Res, $100,555-560$. 